\title{
Caffeine bars used as pre-exercise supplements influence endurance performance, energy metabolism and perception of effort in trained cyclists
}

\author{
Kuno Hottenrott ${ }^{1}$, Stephan Schulze ${ }^{1}$, Sebastian Ludyga ${ }^{1}$, Stefanie Geissler ${ }^{2}$ \\ 1. Department of Sports Science, Martin-Luther-University Halle-Wittenberg, Halle (Saale), Germany. 2. Institute of \\ Agriculture and Nutrition Science, Martin-Luther-University Halle-Wittenberg, Halle (Saale), Germany.
}

Correspondence: Kuno Hottenrott. Address: Department of Sports Science, Martin-Luther-University Halle-Wittenberg, Halle (Saale), Germany. Email: kuno.hottenrott@sport.uni-halle.de

Received: May 24, 2013

DOI : $10.5430 /$ jnep.v4n3p180
Accepted: September 22, 2013 Online Published: November 21, 2013 URL: http://dx.doi.org/10.5430/jnep.v4n3p180

\section{Abstract}

Background: In contrast to caffeine bars, the effect of caffeine intake from tablets and energy drinks on endurance performance has already been investigated. Therefore, the aim of the study is to examine the effects of caffeine bars used as pre-exercise supplements on endurance performance in cycling.

Methods: The present study was designed as a randomized single-blind cross-over placebo-controlled trial. Nine male, trained cyclists completed endurance exercises on a cycling ergometer under the following conditions: ingestion of water (WAT), placebo bars (PLA) and caffeine bars (CAF; $5 \mathrm{mg}$ caffeine/kg bodyweight), respectively, $45 \mathrm{~min}$ prior to the test. After $40 \mathrm{~min}$ at a constant intensity of $75 \% \mathrm{VO}_{2} \mathrm{max}$ (assessed in a previously performed incremental test) load was increased $10 \mathrm{~W} / \mathrm{min}$ until exhaustion.

Results: CAF compared to PLA resulted in a higher maximal power and longer time to exhaustion $(p=.002)$. Surprisingly, concentration of free fatty acids was lower at exhaustion $(p=.004)$, whereas blood lactate levels $(p=.021)$ and heart rate $(p=.008)$ were significantly higher after CAF. Subjects also reported lower received perception of effort at warm-up (0.034), $30 \mathrm{~min}(p=.026)$ and $40 \mathrm{~min}(p=.041)$ only after CAF.

Conclusions: Caffeine bars are useful pre-exercise supplements. Their performance enhancing effect was rather due to a delayed perception of fatigue than an increased lipolysis, proving caffeine as central nervous system stimulant.

\section{Key words}

Caffeine bars, Pre-exercise supplement, Sports nutrition

\section{Introduction}

Caffeine is the most consumed biologically active substance obtained from food, e.g. it is found in coffee, tea and chocolate. The intake of caffeine stimulates the central nervous system, enhances the level of attention and alertness and reduces fatigue ${ }^{[1,2]}$. Depending on the dosage of caffeine possible side effects are tachycardia, hypertension, tremor, 
diuresis and impaired performance ${ }^{[3,4]}$. Several studies have shown that an intake of 3 to $6 \mathrm{mg}$ caffeine per kg bodymass or $450 \mathrm{mg}$ improves performance of athletes especially in endurance exercise ${ }^{[3,5-7]}$ without risking dehydration or imbalance of the electrolyte household ${ }^{[8]}$.

Ingested caffeine is absorbed quickly and nearly complete in the gastrointestinal tract. The highest concentration of caffeine in blood is reached 30 to $60 \mathrm{~min}$ after ingestion ${ }^{[9,10]}$. The performance boosting effect is due to mechanisms on cellular level. Caffeine leads to an increased secretion of catecholamines (adrenaline, noradrenaline), which results in the activation of adenylyl cyclase in fatty tissue and the elevation in the cAMP level ${ }^{[11,12]}$. Consequently, the hormonesensitive lipase (HSL) is activated. The increased lipolysis elevates the plasma concentration of free fatty acids ${ }^{[13,14]}$. Those enter the muscle cells and can be used for oxidative metabolism, whereas the glycolysis is inhibited ("glycogen sparing effect") ${ }^{[15,16]}$. Therefore, the effect of caffeine ingestion on performance is due to an enhanced metabolism of triglycerides in fatty tissue (lypolysis) and oxidation of free fatty acids ${ }^{[17]}$. More importantly, caffeine inhibits the adenosine receptor and has an antagonistic effect on endogenous adenosine ${ }^{[18]}$. Consequently, the release of neurotransmitters is enhanced and stimulates the central nervous system ${ }^{[1,8,19]}$. Furthermore, caffeine improves neuromuscular function by caffeine-stimulated release of calcium ions from the sarcoplasmatic reticulum ${ }^{[20,21]}$.

Because of the performance enhancing effect caffeine has gained growing importance as a supplement before ${ }^{[1]}$ and during exercise ${ }^{[7]}$. Graham et al. ${ }^{[16,22]}$ made clear that the way caffeine is consumed highly influences the effect, e.g. the consumption of coffee results in a limitation of performance benefits. Previous studies have investigated performance markers, such as maximal oxygen consumption, maximal power and time to exhaustion, as well as energy metabolism (blood lactate, glucose and free fatty acids) after caffeine intake in the form of tablets ${ }^{[2]}$, energy drinks ${ }^{[23,24]}$ or electrolyte solutions ${ }^{[15,25]}$. In contrast, the effect of caffeine bars on endurance performance has not been examined sufficiently. Furthermore, studies have shown that the co-ingestion of caffeine and carbohydrates improves the absorption of carbohydrates and their availability for energy supply ${ }^{[26]}$.

Therefore, the aim of the present study was to examine the effects of a caffeine bar as pre-exercise supplement on endurance performance, energy metabolism and rating of perceived exertion (RPE) in trained cyclists. Compared to a placebo bar, only the caffeine bar was expected to enhance performance and delay time to exhaustion in a cycling exercise.

\section{Methods}

\subsection{Subjects}

To provide a low test-retest-variability of performance measures and to prevent performance benefits from repeated ergometer tests ${ }^{[27]}$, subjects had to be trained cyclists. Nine male participants (age: $26 \pm 5$ years; height: $180.4 \pm 6.3 \mathrm{~cm}$; bodyweight: $77.2 \pm 9.8 \mathrm{~kg}$; body fat: $11.0 \pm 3.0 \%$ ) with a regular training of 5-10 h per week were directly recruited from local cycling clubs. Only subjects with a low habitual caffeine intake of approximately 3 cups of coffee (equal to 250 $\mathrm{mg} / \mathrm{d}) 10$ weeks prior to the intervention were included. Exclusion criteria were any cardiovascular, metabolic, neurological, pulmonary or orthopedic complications that could limit performance. Additionally, the intake of hormones, medicaments and drugs led to exclusion. All participants were informed about possible study risks as well as benefits and gave written consent. The study was approved by the Ethics Committee of the Martin-Luther-University HalleWittenberg.

\subsection{Preliminary testing}

All participants underwent a health screening following the S1-guideline of the DGSP ${ }^{[28]}$, including a personal anamnesis, ECG at rest and blood pressure measurement to ensure the safety of performance. 
Body composition was assessed with a bioimpedance measuring device (Tanita, Modell TBF-521, USA). Prior to the experimental trials, subjects performed an incremental test to volitional exhaustion with spirometry (Cortex, Metamax 3b, Germany) on a high performance cycling ergometer (FES, Germany) to assess maximal power and oxygen consumption $\left(\mathrm{VO}_{2} \mathrm{max}\right)$. After a $10 \mathrm{~min}$ warm up at $100 \mathrm{~W}$ the workload was increased $30 \mathrm{~W} / 3 \mathrm{~min}$ until cyclists were unable to maintain a cadence of at least $60 \mathrm{rpm}$. Respiratory parameters and heart rate were recorded continuously. After each stage blood lactate levels were measured in $10 \mu \mathrm{L}$ blood taken from an ear lobe with the enzymatic-amperometric method (Dr. Mueller, model Super GL ambulance, Germany). Collected data were analyzed with WinLactat 3.1 (Mesics GmbH, Germany) to determine lactate threshold according to the model of Dickhuth et al. ${ }^{[29]}$. The maximal oxygen consumption was used as reference value to calculate the workload for the following testing procedures.

\subsection{Experimental design}

The study was designed as a randomized single-blind cross-over placebo-controlled trial (see Table 1). The experiment comprised the repetition of an endurance exercise on a cycling ergometer under the following conditions in a randomized order: ingestion of water (WAT), placebo bars (PLA; carbohydrates: $18.5 \mathrm{~g}$, protein: $5.4 \mathrm{~g}$, fat: $13.5 \mathrm{~g}$, fibre: $2.8 \mathrm{~g}$ ) and caffeine bars (CAF; carbohydrates: $22 \mathrm{~g}$, protein: $3.2 \mathrm{~g}$, fat: $8 \mathrm{~g}$, fibre: $1.1 \mathrm{~g}$, caffeine: $0.1 \mathrm{~g}$ ) respectively, 45 min prior to the test. The exercises were performed on three separate days ( 8 days, 15 days and 22 days after the initial assessment of the maximal power and oxygen consumption). Following the measurement of bodyweight, subjects ingested a weight related dose of caffeine ( $5 \mathrm{mg}$ caffeine per $\mathrm{kg}$ ) or placebo bars (identical number of bars) with $200 \mathrm{ml}$ water/bar or the same amount of water only. An ECG was recorded $10 \mathrm{~min}$ before the endurance exercise. The ergometer test with spirometry included a warm-up period of $10 \mathrm{~min}$ at $50 \% \mathrm{VO}_{2} \mathrm{max}$, followed by a 40 min endurance exercise at $75 \%$ $\mathrm{VO}_{2} \max$. At the end of the endurance exercise the intensity was increased $10 \mathrm{~W} / \mathrm{min}$ until voluntary exhaustion, which was defined as inability to maintain a cadence of at least $60 \mathrm{rpm}$. Similar to the initial incremental test, respiratory parameters and heart rate were recorded continuously. At rest, 10, 20, 30, 40, 50 minutes and after exhaustion RPE was recorded and blood lactate and glucose levels were measured. At rest, 40 minutes and after exhaustion free fatty acids were analyzed in $150 \mu \mathrm{l}$ blood taken from an ear lobe.

Table 1. Experimental design

\begin{tabular}{lllll}
\hline \multirow{2}{*}{ Subjects } & \multicolumn{3}{c}{ Conditions } \\
\cline { 2 - 5 } & 1st day & 8th day & 15th day & 22nd day \\
\hline 1 & INC & WAT & PLA & CAF \\
2 & INC & CAF & WAT & PLA \\
3 & INC & PLA & CAF & WAT \\
4 & INC & WAT & PLA & CAF \\
5 & INC & CAF & WAT & PLA \\
6 & INC & PLA & CAF & WAT \\
7 & INC & WAT & PLA & CAF \\
8 & INC & CAF & WAT & PLA \\
9 & INC & PLA & CAF & WAT \\
\hline
\end{tabular}

Notes. INC: initial incremental ergometer test; WAT: ingestion of water $45 \mathrm{~min}$ before the endurance exercise; PLA: ingestion of placebo bars 45 min before the endurance exercise; CAF: ingestion of caffeine bars $45 \mathrm{~min}$ before the endurance

\subsection{Standardization procedures}

The exercise tests were performed at a room temperature of $20^{\circ} \mathrm{C}$, the same time of day and with identical seat position. Subjects were asked to refrain from the consumption of caffeine over the whole intervention period, starting three days before the initial assessment. Furthermore, the last meal had to be 3 hours prior to the test. The nutrition within $12 \mathrm{~h}$ before the initial assessment was recorded with a protocol. In preparation of the exercise tests participants had to follow the 
protocol to guarantee a comparable nutrition. Between the tests under different conditions athletes maintained their regular training at low to moderate intensity, but did not take part in competitions.

\subsection{Statistics}

Statistical analysis was performed on SPSS version 19.0. After a histogram analysis data were checked for normal distribution with Kolmogorov-Smirnoff-Test. In case of normal distribution and metric data Student's T-test was applied. The non-parametric Wilcoxon test was used for analysis of ordinal data with skewed distribution. A criterion alpha level of $p \leq .05$ was used to determine statistical significance. All data are reported as mean $\pm \mathrm{SD}$. The following variables were selected to identify significant differences between the test conditions: maximal power [W], time to exhaustion [min], oxygen consumption $\left[\mathrm{ml}^{-1} \mathrm{~min}^{-1} \mathrm{~kg}^{-1}\right]$, RER, heart rate $\left[\right.$ beats $\left.\mathrm{min}^{-1}\right]$, RPE, blood lactate $\left[\mathrm{mmol} \mathrm{l}^{-1}\right]$, blood glucose $\left[\mathrm{mmol}^{-1}\right]$, free fatty acids $\left[\mathrm{mmol}^{-1}\right]$.

\section{Results}

All subjects successfully completed the study. The results of the initial incremental ergometer test are shown in Table 2 . The average workload $\left(75 \% \mathrm{VO}_{2} \max \right)$ for the endurance exercises was $246.7 \pm 27.4 \mathrm{~W}$. At rest (pre-exercise) there were no differences in heart rate, oxygen consumption and RPE between the conditions. As expressed in Figure 1, the ingestion of caffeine bars compared to conditions WAT and PLA resulted in a higher maximal power $(p=.002)$ and longer time to exhaustion (WAT vs CAF: $p=.001$; PLA vs CAF: $p=.002$ ).

Table 2. Results of the initial incremental test (mean \pm SD)

\begin{tabular}{lllll}
\hline $\mathrm{VO}_{2 \max }\left[\mathrm{ml} \cdot \mathrm{min}^{-1} \mathrm{~kg}^{-1}\right]$ & $\mathrm{P}_{\max }[\mathrm{W}]$ & $\mathrm{HR}_{\max }\left[\mathrm{min}^{-1}\right]$ & $\mathrm{LA}_{\max }[\mathrm{mmol} / 1]$ & $\mathrm{RER}_{\max }$ \\
\hline $58.0 \pm 5.6$ & $400.3 \pm 20.0$ & $182.4 \pm 6.5$ & $10.02 \pm 0.79$ & $1.14 \pm 0.05$ \\
\hline
\end{tabular}

Notes. $\mathrm{VO}_{2}$ max: maximal oxygen consumption; Pmax: maximal workload; HRmax: maximal heart rate; LAmax: maximal blood lactate; RERmax: maximal respiratory exchange ratio
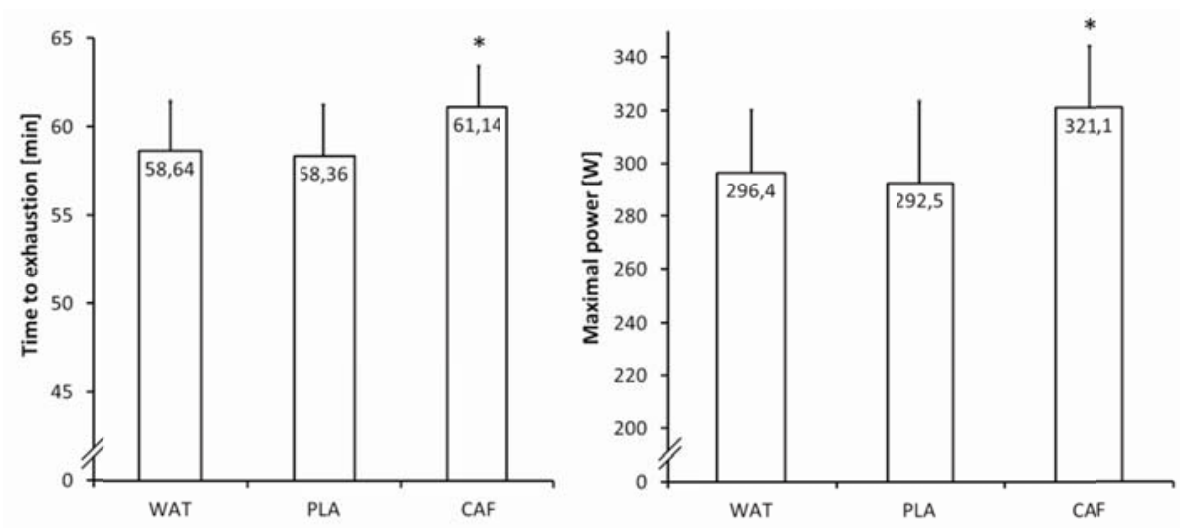

Figure 1. Time to exhaustion and maximal power after ingestion of water (WAT), placebo bars (PLA) and caffeine bars (CAF)

Respiratory parameters: The flow of respiratory parameters throughout the exercise is presented in Table 3. Statistically significant differences of the oxygen consumption were found between conditions WAT and PLA during the warm up period ( $p=.035$ ) and after 10 minutes $(p=.037)$. The ingestion of caffeine bars resulted in a statistical significantly higher RER at rest (WAT vs CAF: $p=.007$; PLA vs CAF: $p=.015$ ). Throughout the endurance exercise no differences in RER were found between the conditions. However, the RER was statistical significantly higher after ingestion of caffeine bars compared to water at exhaustion $(p=.002)$. 
Table 3. Respiratory parameters measured under different conditions before, during and after the endurance test (mean $\pm \mathrm{SD})$

\begin{tabular}{llllllllll}
\hline & CON & Rest & Warm-Up & $\mathbf{1 0}$ min & 20 min & 30 min & 40 min & EX & Post \\
\hline $\mathrm{VO}_{2}$ & WAT & $6.4 \pm 2.0$ & $26.0 \pm 3.5$ & $43.5 \pm 4.1$ & $44.8 \pm 3.9$ & $44.6 \pm 4.1$ & $45.2 \pm 4.8$ & $50.4 \pm 6.8$ & $23.4 \pm 6.1$ \\
{$\left[\mathrm{ml}^{-1} \min ^{-1}\right.$} & PLA & $7.4 \pm 2.0$ & $27.3 \pm 2.9^{\#}$ & $45.1 \pm 3.2^{\#}$ & $44.5 \pm 3.0$ & $46.0 \pm 4.2$ & $46.0 \pm 4.2$ & $49.4 \pm 5.5$ & $21.2 \pm 7.9$ \\
$\left.\mathrm{~kg}^{-1}\right]$ & $\mathrm{CAF}$ & $6.6 \pm 1.3$ & $26.4 \pm 2.5$ & $43.6 \pm 3.5$ & $44.0 \pm 3.4$ & $44.5 \pm 3.4$ & $44.5 \pm 3.4$ & $52.2 \pm 7.4$ & $25.4 \pm 9.8$ \\
& WAT & $0.72 \pm 0.07$ & $0.85 \pm 0.03$ & $0.88 \pm 0.05$ & $0.87 \pm 0.05$ & $0.87 \pm 0.07$ & $0.87 \pm 0.05$ & $0.97 \pm 0.05$ & $0.86 \pm 0.04$ \\
$\mathrm{RER}$ & PLA & $0.74 \pm 0.05$ & $0.84 \pm 0.05$ & $0.87 \pm 0.04$ & $0.87 \pm 0.04$ & $0.86 \pm 0.04$ & $0.86 \pm 0.03$ & $0.95 \pm 0.07$ & $0.86 \pm 0.12$ \\
& $\mathrm{CAF}$ & $0.83 \pm 0.07^{* \#}$ & $0.87 \pm 0.05$ & $0.90 \pm 0.04$ & $0.90 \pm 0.04$ & $0.89 \pm 0.04$ & $0.89 \pm 0.04$ & $1.02 \pm 0.03^{\#}$ & $0.90 \pm 0.09$ \\
\hline
\end{tabular}

${ }^{*} p<.05$ compared to PLA; ${ }^{*} p<.05$ compared to WAT;

WAT: ingestion of water 45 min before the endurance exercise; PLA: ingestion of placebo bars 45 min before the endurance exercise; CAF: ingestion of caffeine bars 45 min before the endurance; EX: exhaustion; statistical analysis for RER and $\mathrm{VO}_{2}$ was performed with Student's T-test

Heart rate: Heart rate (see Table 4) was significantly higher after ingestion of caffeine bars vs water at $10(p=.05)$ and 20 $\min (p=.037)$. Compared to conditions WAT and PLA the ingestion of caffeine bars resulted in a significantly higher heart rate at exhaustion $(p=.008)$, which was similar to the maximal heart rate measured in the initial incremental test. This difference was also found 3 min post-exercise between the conditions WAT and CAF $(p=.017)$.

Table 4. Heart rate and RPE measured under different conditions before, during and after the endurance test (mean \pm SD)

\begin{tabular}{llllllllll}
\hline & CON & Rest & Warm-Up & 10 min & 20 min & 30 min & 40 min & EX & Post \\
\hline \multirow{2}{*}{ RPE } & WAT & - & $10.0 \pm 1.6$ & $13.6 \pm 1.2$ & $15.0 \pm 1.0$ & $16.3 \pm 1.4$ & $17.6 \pm 1.3$ & $19.1 \pm 1.0$ & - \\
{$[6-20]$} & PLA & - & $10.3 \pm 1.2$ & $13.8 \pm 1.0$ & $15.1 \pm 0.8$ & $16.7 \pm 1.1$ & $17.7 \pm 1.6$ & $19.3 \pm 0.7$ & - \\
& CAF & - & $9.3 \pm 1.5^{*}$ & $13.3 \pm 1.0$ & $14.3 \pm 0.7$ & $15.3 \pm 1.0 *^{\#}$ & $16.2 \pm 1.2 *^{\#}$ & $19.2 \pm 0.8$ & - \\
Heart rate & WAT & $65 \pm 7$ & $113 \pm 10$ & $145 \pm 10$ & $154 \pm 7$ & $161 \pm 6$ & $165 \pm 7$ & $177 \pm 10$ & $130 \pm 10$ \\
{$\left[1 \mathrm{~min}^{-1}\right]$} & PLA & $68 \pm 7$ & $114 \pm 8$ & $152 \pm 9$ & $158 \pm 8$ & $163 \pm 9$ & $169 \pm 8$ & $178 \pm 10$ & $136 \pm 19$ \\
& CAF & $67 \pm 10$ & $116 \pm 9$ & $151 \pm 7^{\#}$ & $157 \pm 7^{\#}$ & $163 \pm 7$ & $168 \pm 8$ & $183 \pm 9 *^{\#}$ & $141 \pm 20^{\#}$ \\
\hline
\end{tabular}

${ }^{*} p<.05$ compared to PLA; ${ }^{*} p<.05$ compared to WAT;

WAT: ingestion of water $45 \mathrm{~min}$ before the endurance exercise; PLA: ingestion of placebo bars 45 min before the endurance exercise; CAF: ingestion of caffeine bars 45 min before the endurance; EX: exhaustion; statistical analysis for heart rate and RPE was performed with Wilcoxon test

Table 5. Blood lactate, glucose and free fatty acids measured under different conditions before, during and after the endurance test (mean $\pm \mathrm{SD})$

\begin{tabular}{|c|c|c|c|c|c|c|c|c|c|}
\hline & CON & Rest & Warm-Up & $10 \mathrm{~min}$ & $20 \mathrm{~min}$ & $30 \mathrm{~min}$ & $40 \mathrm{~min}$ & EX & Post \\
\hline \multirow{3}{*}{$\begin{array}{l}\text { Lactate } \\
{\left[\mathrm{mmoll}^{-1}\right]}\end{array}$} & WAT & $0.65 \pm 0.25$ & $0.80 \pm 0.52$ & $1.92 \pm 0.84$ & $1.92 \pm 0.79$ & $2.04 \pm 0.79$ & $2.25 \pm 1.15$ & $4.97 \pm 1.26$ & $3.98 \pm 1.23$ \\
\hline & PLA & $1.22 \pm 0.37^{\#}$ & $0.64 \pm 0.11$ & $2.24 \pm 0.74$ & $2.37 \pm 0.71$ & $2.57 \pm 0.89^{\#}$ & $2.81 \pm 1.21^{\#}$ & $5.19 \pm 1.60$ & $4.60 \pm 1.43$ \\
\hline & $\mathrm{CAF}$ & $1.38 \pm 0.54^{\#}$ & $0.95 \pm 0.28 *$ & $2.27 \pm 0.88$ & $2.53 \pm 0.93^{\#}$ & $2.62 \pm 0.98^{\#}$ & $2.57 \pm 0.84$ & $7.25 \pm 1.41^{* \#}$ & $6.66 \pm 1.55^{* \#}$ \\
\hline \multirow{3}{*}{$\begin{array}{l}\text { Glucose } \\
{\left[\mathrm{mmol}^{-1} \mathrm{l}^{-1}\right]}\end{array}$} & WAT & $4.70 \pm 0.51$ & $4.17 \pm 0.69$ & $4.15 \pm 0.68$ & $4.28 \pm 0.34$ & $4.43 \pm 0.49$ & $4.79 \pm 0.72$ & $4.82 \pm 0.71$ & $5.61 \pm 0.90$ \\
\hline & PLA & $4.75 \pm 0.53$ & $3.96 \pm 0.59$ & $3.82 \pm 0.46$ & $4.13 \pm 0.43$ & $4.39 \pm 0.25$ & $4.63 \pm 0.42$ & $4.73 \pm 0.63$ & $5.50 \pm 0.69$ \\
\hline & CAF & $4.93 \pm 0.54$ & $3.98 \pm 0.85$ & $3.82 \pm 0.57$ & $4.11 \pm 0.37$ & $4.34 \pm 0.44$ & $4.50 \pm 0.60$ & $4.76 \pm 0.79$ & $5.84 \pm 1.21$ \\
\hline \multirow{3}{*}{$\begin{array}{l}\text { Free fatty } \\
\text { acids } \\
{\left[\mathrm{mmol}^{-1} \mathrm{l}^{-1}\right]}\end{array}$} & WAT & $0.34 \pm 0.12$ & - & - & - & - & $0.44 \pm 0.18$ & $0.45 \pm 0.16$ & - \\
\hline & PLA & $0.29 \pm 0.07$ & - & - & - & - & $0.35 \pm 0.11$ & $0.39 \pm 0.14$ & - \\
\hline & CAF & $0.26 \pm 0.10$ & - & - & - & - & $0.31 \pm 0.11^{\#}$ & $0.31 \pm 0.11^{\#}$ & - \\
\hline
\end{tabular}

$* p<.05$ compared to PLA; ${ }^{*} p<.05$ compared to WAT;

WAT: ingestion of water 45 min before the endurance exercise; PLA: ingestion of placebo bars 45 min before the endurance exercise; CAF: ingestion of caffeine bars 45 min before the endurance; EX: exhaustion; statistical analysis for free fatty acids and glucose was performed with Student's T-test; statistical analysis for lactate was performed with Wilcoxon test 
Energy metabolism: As shown in Table 5, the intake of the placebo bar and the caffeine bar compared to water resulted in higher lactate levels at rest (WAT vs PLA: $p=.011$; WAT vs CAF: $p=.012$ ). Differences between WAT and PLA were also found at 30 and 40 minutes $(p=.008)$. After the ingestion of caffeine bars subjects had higher lactate levels than in WAT at almost all measuring time points (20 min: $p=.028$; $30 \mathrm{~min}: p=.051$; exhaustion: $p=.011$; post-exercise: $p=$ .008 ), except warm-up, $10 \mathrm{~min}$ and $40 \mathrm{~min}$. Differences of lactate levels between conditions PLA and CAF were statistically significant at warm-up $(p=.012)$, exhaustion $(p=.021)$ and 3 min post-exercise $(p=.021)$. In contrast, the pre-exercise supplements had no impact on blood glucose levels. At exhaustion the concentration of free fatty acids was significantly lower after the ingestion of caffeine bars (WAT vs CAF: $p=.012$; PLA vs CAF: $p=.004$ ). Additionally, a significant difference between WAT and CAF was also found at $40 \mathrm{~min}(p=.04)$.

Perceived exertion: During the warm up period the RPE (see Table 4) was significantly lower after the ingestion of caffeine bars compared to the placebo bar $(p=.034$ ). At 30 (WAT vs CAF: $p=.037$; PLA vs CAF: $p=.026$ ) and 40 min (WAT vs CAF: $p=.01$; PLA vs CAF: $p=.041$ ) subjects reported a lower RPE after the ingestion of caffeine bars only.

\section{Discussion}

The effect of caffeine on sports performance has already been proved ${ }^{[3,5]}$. However, the underlying mechanisms for caffeine-improved performance are not entirely clear, although the antagonism of adenosine receptors ${ }^{[30]}$ and an increase in catecholamine release ${ }^{[31,32]}$ provide an explanation in part. Additionally, caffeine is assumed to increase lipolysis, so that free fatty acids are more available for energy supply ${ }^{[33]}$, whereas the depletion of muscle glycogen is reduced especially during submaximal exercise intensity ${ }^{[34]}$.

Although subjects achieved higher maximal power and a longer time to exhaustion after the ingestion of caffeine bars in the present study, the effect seems not to be due to an increased lipolysis. On the contrary, the concentration of free fatty acids was significantly lower compared to the other test conditions at exhaustion. In contrast to Spriet et al. ${ }^{[34]}$ Graham et al. ${ }^{[4]}$ concluded that the ergogenic effect of caffeine is the result of a conversion of the fat and carbohydrate metabolism. Taking into account that the lactate levels were higher after ingestion of caffeine bars, the mobilization of free fatty acids was reduced possibly due to the combined intake of caffeine and carbohydrates. Therefore, a higher insulin concentration through consumption of quickly available carbohydrates in the bars could have affected the lipolysis. In contrast, Thong et al. ${ }^{[35]}$ showed that the caffeine's antagonism of the adenosine receptor induces an insulin resistance and inhibits glucose absorption in muscle cells. This mechanism might explain similar blood glucose levels between the test conditions ${ }^{[35,36]}$. Furthermore, the increased breakdown of glucose indicated a higher oxygen consumption after the ingestion of bars (both with and without caffeine), which was shown by an elevated RER already at rest.

Findings of the present study prove the previously reported ergogenic effect of caffeine on the RPE ${ }^{[37,38]}$, as the perceived exertion was rated lower after ingestion of caffeine bars compared to other conditions at exhaustion. Laurent et al. ${ }^{[38]}$ reported an increased release of endorphins after caffeine intake, which influenced the fatigue-related pain perception after exercises at different intensities positively. Consequently, in the present study a lower perceived exertion at submaximal intensities after caffeine intake might be due to the increased release of endorphins and the inhibition of the adenosine receptor combined. Doherty and Smith ${ }^{[37]}$ showed that the impact of caffeine on the RPE increases with the maximal oxygen consumption of subjects.

In conclusion, the effect of caffeine on perceived exertion after $40 \mathrm{~min}$ at $75 \% \mathrm{VO}_{2}$ max has contributed to an improved maximal power and longer time to exhaustion after ingestion of caffeine bars compared to the other conditions. As subjects had a delayed perception of fatigue exercise capacity was increased (higher RER and lactate levels). Hogervorst et al. ${ }^{[39]}$ also showed that caffeine bars improve physiological and mental performance. Whereas increased lactate levels and lower RPE account for the ergogenic aid of caffeine, the expected effects on blood glucose and concentration of free fatty 
acids were not proven. Therefore, caffeine seems to work as central nervous system stimulant that delays the perception of fatigue $^{[40]}$.

\section{Limitations}

In the present study only subjects were blinded to treatment, because the investigator prepared the supplements, knowing the test condition. Another limitation of the study was a small sample size of only 9 subjects. However, the low number of participants was selected according to previous investigations in this field ${ }^{[22,23]}$. Furthermore, the weight related dose of the caffeine bars used by the authors is not suitable for an implementation into practice, because, for instance, an athlete of $100 \mathrm{~kg}$ bodyweight would have to consume 5 bars. This high intake of supplements could possibly affect performance and digestion during exercise. Therefore, especially in high impact sports the use of caffeine bars is not recommended. Further limitations were slight differences of the ingredients between the placebo and the caffeine bar. However, the composition of the caffeine bar was adjusted to neutralize the taste of caffeine, so that subjects were not able to recognize it as such. The interpretation of results is also limited as it was not examined whether the improved performance depended on the co-ingestion of carbohydrates and caffeine or the intake of caffeine only. Therefore, future studies should seek to compare the effects of caffeine supplementation in the form of bars (caffeine and carbohydrates) with pure caffeine ingestion (e.g. tablets).

\section{Conclusion}

As the co-ingestion of caffeine and carbohydrates in form of bars led to improved sports performance, it has to be considered as an important and useful pre-exercise supplement. Cyclists might also benefit from the ingestion of caffeine bars before intensive training sessions and competitions, because it delays the perception of fatigue and therefore allows higher workloads. The dose of caffeine bars in the present study did not affect performance or digestion and can be considered safe for athletes with a similar bodyweight.

\section{References}

[1] Nehlig A, Daval JL, Debry G. Caffeine and the central nervous system: mechanisms of action, biochemical, metabolic and psychostimulant effects. Brain Res.Brain Res. Rev. 1992; 17: 139-170. http://dx.doi.org/10.1016/0165-0173(92)90012-B

[2] Lorist MM, Tops M. Caffeine, fatigue, and cognition. Brain Cogn. 2003; 53: 82-94. http://dx.doi.org/10.1016/S0278-2626(03)00206-9

[3] Graham TE, Spriet LL. Metabolic, catecholamine, and exercise performance responses to various doses of caffeine. J. Appl. Physiol. 1995; 78: 867-874. PMid:7775331

[4] Graham TE, Battram DS, Dela F, El-Sohemy A, Thong FS. Does caffeine alter muscle carbohydrate and fat metabolism during exercise? Appl. Physiol. Nutr. Metab. 2008; 33: 1311-1318. PMid:19088793 http://dx.doi.org/10.1139/H08-129

[5] Cox GR, Desbrow B, Montgomery PG, Anderson ME, Bruce CR. Effect of different protocols of caffeine intake on metabolism and endurance performance. J. Appl. Physiol. 2002; 93: 990-999. PMid:12183495

[6] Cureton KJ, Warren GL, Millard-Stafford ML, Wingo JE, Trilk J, Buyckx M. Caffeinated sports drink: ergogenic effects and possible mechanisms. Int. J. Sport Nutr. Exerc. Metab. 2007; 17: 35-55. PMid:17460332

[7] Ganio MS, Klau JF, Casa DJ, Armstrong LE, Maresh CM. Effect of caffeine on sport-specific endurance performance: a systematic review. J. Strength Cond. Res. 2009; 23: 315-324. PMid:19077738 http://dx.doi.org/10.1519/JSC.0b013e31818b979a

[8] Paluska SA. Caffeine and exercise. Curr. Sports Med. Rep. 2003; 2: 213-219. PMid:12834577 http://dx.doi.org/10.1249/00149619-200308000-00008

[9] Liguori A, Hughes JR, Grass JA. Absorption and subjective effects of caffeine from coffee, cola and capsules. Pharmacol. Biochem. Behav. 1997; 58: 721-726. http://dx.doi.org/10.1016/S0091-3057(97)00003-8

[10] Mumford GK, Benowitz NL, Evans SM, Kaminski BJ, Preston KL, Sannerud CA, Silverman K, Griffiths RR. Absorption rate of methylxanthines following capsules, cola and chocolate. Eur. J. Clin. Pharmacol. 1996; 51: 319-325. PMid:9010706 http://dx.doi.org/10.1007/s002280050205

[11] Waldeck B. Sensitization by caffeine of central catecholamine receptors Journal of Neural Transmission. 1973; 34: 61-72. PMid:4714594 http://dx.doi.org/10.1007/BF01244827

[12] Fredholm BB. Are methylxanthine effects due to antagonism of endogenous adenosine? TIPS. 1980; 1: 129-132.

http://dx.doi.org/10.1016/0165-6147(79)90046-4 
[13] Beavo JA, Rogers NL, Crofford OB, Hardman JG, Sutherland EW, Newman EV. Effects of xanthine derivatives on lipolysis and on adenosine 3', 5'-monophosphate phosphodiesterase activity. Mol. Pharmacol. 1970; 6: 597-603. PMid:4322367

[14] Severson DL. Regulation of lipid metabolism in adipose tissue and heart. Can. J. Physiol. Pharmacol. 1979; 57: 923-937.

[15] Kovacs EMR, Stegen JHCH, Brouns F. Effect of caffeinated drinks on substrate metabolism, caffeine excretion, and performance. J. Appl. Physiol. 1998; 85: 709-715. PMid:9688750

[16] Graham TE. Caffeine and exercise: metabolism, endurance and performance. Sports Med. 2001; 31: 785-807. PMid:11583104 http://dx.doi.org/10.2165/00007256-200131110-00002

[17] Pasman WJ, van Baak MA, Jeukendrup AE, de Haan A. The effect of different dosages of caffeine on endurance performance time. Int. J. Sports Med. 1995; 16: 225-230. PMid:7657415 http://dx.doi.org/10.1055/s-2007-972996

[18] Snyder SH, Katims JJ, Annau Z, Bruns RF, Daly JW. Adenosine receptors and behavioral actions of methylxanthines. Proc. Natl. Acad. Sci. 1981; 78: 3260-3264. PMid:6265942 http://dx.doi.org/10.1073/pnas.78.5.3260

[19] Keisler BD, Armsey TD. Caffeine as an ergogenic aid. Curr. Sports Med. Rep. 2006; 5: 215-219. PMid:16822345 http://dx.doi.org/10.1097/01.CSMR.0000306510.57644.a7

[20] Anselme F, Collomp K, Mercier B, Ahmaïdi S, Prefaut C. Caffeine increases maximal anaerobic power and blood lactate concentration. Eur. J. Appl. Physiol. Occup. Physiol.1992; 65: 188-191. PMid:1396643 http://dx.doi.org/10.1007/BF00705079

[21] Tarnopolsky MA, Cupido C. Caffeine potentiates low frequency skeletal muscle force in habitual and nonhabitual caffeine consumers. J. Appl. Physiol. 2000; 89: 1719-1724. PMid:11053318

[22] Graham TE, Hibbert E, Sathasivam P. Metabolic and exercise endurance effects of coffee and caffeine ingestion. J. Appl. Physiol. 1998; 85: 883-889. PMid:9729561

[23] Ivy J, Kammer L, Ding Z, Wang B, Bernard JR, Liao Y, HwangImproved J. Cycling Time-Trial Performance After Ingestion of a Caffeine Energy Drink. International Journal of Sport Nutrition and Exercise Metabolis. 2009; 19: 61-78. PMid:19403954

[24] Peltier SL, Vincent L, Millet GY, Sirvent P, Morin J, Guerraz M, Geyssant A, Lescuyer J, Feasson L, Messonnier L. Effects of carbohydrates-BCAAs-caffeine ingestion on performance and neuromuscular function during a 2-h treadmill run: a randomized, doubleblind, cross-over placebo-controlled study. Journal of the International Society of Sports Nutrition. 2011; 8: 22-26. PMid:22152427 http://dx.doi.org/10.1186/1550-2783-8-22

[25] Ganio MS, Klau JF, Lee EC, Yeargin SW, McDermott BP, Buyckx M. Effect of various carbohydrate-electrolyte fluids on cycling performance and maximal voluntary contraction. Int J Sport Nutr Exerc Metab. 2010; 20: 104-14. PMid:20479483

[26] Van Nieuwenhoven MA, Brummer RM, Brouns F. Gastrointestinal function during exercise: comparison of water, sports drink, and sports drink with caffeine. J Appl Physiol. 2000; 89: 1079-1085. PMid:10956354

[27] Hopkins, W.G., Schabort, E.J., Hawley, J.A. Reliability of Power in Physical Performance Tests Sports Med. 2001; 31: 211-234.

[28] DGSP. S1-Leitlinie Vorsorgeuntersuchung im Sport. 2007. http://www.dgsp.de/_downloads/allgemein/S1_Leitlinie.pdf.

[29] Dickhuth HH, Aufenanger W, Rokitzki L, Huonker M, Keul J. Lactate performance curve, performance assessment and training management of high performance athletes in middle- and longdistance running. International Journal of Sports Medicine. 1988; 9: 387-395.

[30] Davis JM, Zhao Z, Stock HS, Mehl KA, Buggy J, Hand GA. Central nervous system effects of caffeine and adenosine on fatigue. Am J Physiol Regul Integr Comp Physiol. 2003; 284: 399-404.

[31] Jackman M, Wendling P, Friars D, Graham TE. Metabolic, catecholamine, and endurance responses to caffeine during intense exercise. J Appl Physiol. 1996; 81: 1658-1663. PMid:8904583

[32] Van Soeren MH, Sathasivam P, Spriet LL, Graham TE. Caffeine metabolism and epinephrine responses during exercise in users and nonusers, Journal of Applied Physiology. 1993, 75: 805-812. PMid:8226485

[33] Costill DL, Dalsky GP, Fink WJ. Effects of caffeine ingestion on metabolism and exercise performance. Med. Sci .Sports 1978; 10: 155-158. PMid:723503

[34] Spriet LL, MacLean DA, Dyck DJ, Hultman E, Cederblad G, Graham TE. Caffeine ingestion and muscle metabolism during prolonged exercise in humans. Am. J. Physiol. 1992; 262: 891-898.

[35] Thong FS, Derave W, Kiens B, Graham TE, Ursø B, Wojtaszewski JF, Hansen BF, Richter EA. Caffeine-induced impairment of insulin action but not insulin signaling in human skeletal muscle is reduced by exercise. Diabetes. 2002; 51: 583-590. PMid:11872654

[36] Thong FS, Graham TE. Caffeine-induced impairment of glucose tolerance is abolished by b-adrenergic receptor blockade in humans. J. Appl. Physiol. 2002; 92: 2347-2352. PMid:12015346

[37] Doherty M, Smith, PM. Effects of caffeine ingestion on rating of perceived exertion during and after exercise: a meta-analysis. Scand J Med Sci Sports. 2005; 15: 69-78. PMid:15773860 http://dx.doi.org/10.1111/j.1600-0838.2005.00445.x

[38] Laurent D, Schneider KE, Prusaczyk WK, Franklin C, Vogel SM, Krssak M, Petersen KF, Goforth HW, Shulman GI. Effects of caffeine on muscle glycogen utilization and the neuroendocrine axis during exercise. J. Clin. Endocrinol. Metab. 2000; 85: $2170-2175$. PMid:10852448 http://dx.doi.org/10.1210/jc.85.6.2170

[39] Hogervorst E, Bandelow S, Schmitt J, Jentjens R, Oliveira M, Allgrove J, Carter T, Gleeson M. Caffeine improves physical and cognitive performance during exhaustive exercise. Med. Sci. Sports Exerc. 2008; 40: 1841-1851. PMid:18799996 http://dx.doi.org/10.1249/MSS.0b013e31817bb8b7

[40] Tarnopolsky MA. Caffeine and creatine use in sport. Ann. Nutr. Metab. 2010; 57: 1-8. PMid:21346331 http://dx.doi.org/10.1159/000322696

Published by Sciedu Press 